\title{
An optimal control model of COVID-19 pandemic: a comparative study of five countries
}

\author{
Ali Khaleel Dhaiban ${ }^{1}$ D $\cdot$ Baydaa Khalaf Jabbar ${ }^{2}$
}

Accepted: 4 November 2020 / Published online: 19 January 2021

(c) Operational Research Society of India 2021

\begin{abstract}
This paper formulates an optimal control model of COVID-19 pandemic spreading. We discuss the health sector performance of Argentina, Hungary, Egypt, Malaysia, and Iraq. A mathematical model describes an actual case number of COVID-19. We investigate three strategies depend on recovery rate, death rate, and together (optimal). These strategies represent the percent of the health sector development. The explicit solution of the model using the Pontryagin maximum principle is derived. The results showed the ranking of countries based on the new percent of the recovery and death cases. A new percent as a result to the control variable value (health sector development). Also, the development percent of the health sector of each country, was determined. For example, 0.005 led to a significant reduce the death rates in Malaysia. Meanwhile, a half of death rates could reduce by this percent in Egypt.
\end{abstract}

Keywords COVID-19 pandemic $\cdot$ Optimal control · Argentina $\cdot$ Hungary $\cdot$ Egypt · Malaysia $\cdot$ Iraq

JEL Classification C44 · C61

Ali Khaleel Dhaiban

khaleel.a@mohesr.gov.iq

Baydaa Khalaf Jabbar

baydaakhalaf2611@gmail.com

1 Department of Statistics, College of Administration and Economic, Mustansiriyah University, Baghdad, Iraq

2 Department of Chemistry, College of Education Ibn al-Haytham, Baghdad University, Baghdad, Iraq 


\section{Introduction}

Covid-19 pandemic threaten a life of millions of people around the world. Also, it led a huge loss in the world economy and trade exchange between countries. The pandemic has spread around the world during a few months. Most nations have isolated to face this virus and decrease the losses. Several studies have investigated COVID-19 virus around the world. The target understanding the composition of the virus and find the appropriate treatment.

To diagnose the symptoms of the disease, Wang et al. [1] clarified the long period of virus incubation without clinical symptoms earlier. It represents the most dangerous factor of a pandemic. Symptoms of COVID-19 and SARS-CoV2-negative, such as fever, cough, levels of creatinine and Procalcitonin (PCT), were studied by Chen et al. [2]. For younger age patients, they discussed the difference in urea and creatinine, as well as parameters of routine blood work-up. Xu et al. [3] considered SARS-CoV-2 or liver injury may lead to COVID-19 injury. Also, they clarified the pathological features of COVID-19 are like to SARS and MERS. The main symptoms of the pregnant that injured by COVID-19 were indicated by X. Chen et al. [4]. Pregnant suffered from fever and cough, without vertical transmission of the virus in late pregnancy. World health organization (WHO) addressed the effect of COVID-19 pandemic on the mental health of children and elderly [5]. According to tests on 1014 patients in China, Ai et al. [6] clarified the chest CT is highly sensitive to virus diagnosis compared with reverse-transcription chain reaction.

As a suggested treatment, Lipsitch et al. [7] suggested using the treatment of influenza pandemic in 2009 to treat Covid-19 patients, with provide surveillance systems. Clinical trials in many hospitals in seven cities and more than 100 patients in China were conducted by Gao et al. [8]. They recommended using Chloroquine phosphate that used with malaria disease to treat COVID-19 patients. Zhou et al. [9] collected Viral RNA samples from survivors and deaths to explore the factors that cause death in hospital by using multivariable logistic regression.

As mathematical models, several researchers have formulated mathematical models to describe pandemics. Models have simulated the actual cases of diseases. Then clarify the effect of many factors on the spreading, such as vaccination, weather, isolation, and so on. The optimal control model is an example of these models. Lee et al. [10] determined the effect of treatment and isolation strategies, with a limited of antiviral on the spread of influenza. Three models of optimal control of the SIR epidemic were investigated by Hansen and Day [11] to reduce the outbreak size. Tuite et al. [12] reduced the potential effects of the cholera epidemic in Haiti by using the spread control strategies. The dengue vaccine as a control variable to paediatric and random mass, were discussed by Rodrigues et al. [13]. The total implementation costs and the number of infected cases of tuberculosis were reduced by P. Rodrigues et al. [14] by using different scenarios. Moualeu et al. [15] formulated a mathematical model of tuberculosis cases with lost-sight and latently infected. Pang et al. [16] simulated the actual 
cases of measles transmission, then suggest the optimal strategy of vaccine in US (1951-1962). Ebola virus spreading in West Africa was addressed by Rachah and Torres $[17,18]$. The effect of vaccination on the virus spreading over time with different cases was investigated by the first paper. Meanwhile, the second paper addressed a control on the Ebola virus, with several strategies of exposed and vaccine. Gao and Huang [19] recommended a strategy with three controls to reduce the tuberculosis cases and the intervention cost.

Follows this introduction, information about COVID-19 pandemic spreading in Sect. 2. Section 3 describes the optimal control model and its explicit solution by using the Pontryagin maximum principle (PMP). The results and its explanation of several models are collected in Sect. 4. Section 5 describes conclusions and the future suggested works.

\section{COViD-19 pandemic spreading}

Wuhan, Hubei, China is the source of the first cases of COVID-19 that identified in December 2019 [2]. In January, the virus moved into three Asian countries; Thailand, Japan, and South Korea [20]. At the end of February, the cases have been registered in Europe, North America, Asia, African and Latin American [21]. At the begging of March, more than ten thousand patients have been dead out of China [1]. Until today, 1 July 2020, more than (10) million confirmed cases with more than (500) thousand deaths in the world [22].

The first case registered in Malaysia on 26 January [23], While in Egypt on 19 February [24]. 24 February, the first case registered in Iraq, while in Argentina and Hungary in 5 March [25]. Argentina reached to more than 100 cases by only (9) days, while Malaysia in (44) days. Other countries, Hungary, Iraq, and Egypt have reached to more than 100 cases in 17,22 , and 25 days, respectively.

\section{Optimal control model}

The objective function of optimal control model is defined by:

$$
\operatorname{Min} \cdot J=\sum_{t=0}^{T-1}\{x(t)+y(t)\}^{2}
$$

Subject to state equations of inpatient, recover and death:

$$
\begin{gathered}
\Delta I(t)=\beta(t) I(t)-\{\mu(t)+x(t)\} I(t)-\{N(t)+y(t)\} I(t) \\
\Delta R(t)=\{\mu(t)+x(t)\} I(t) \\
\Delta D(t)=\{N(t)+y(t)\} I(t)
\end{gathered}
$$

where, 
$x(t), y(t)$ : The control variables.

$I(t)$ : The percent of inpatient cases.

$R(t)$ : The percent of recovery cases.

$D(t)$ : The percent of death cases.

$\beta(t)$ : The percent of the new cases to the inpatient cases.

$\mu(t)$ : The percent of the recovery cases to the inpatient cases.

$N(t)$ : The percent of the death cases to the inpatient cases.

$\Delta I(t)=I(t+1)-I(t)$

The total number of inpatients increases by the new cases and decrease by the number of recovering and death every day (Eq. 2). Equations (3) and (4) represent the total number of recovering and death, respectively. Control variables represent the percentage of increase of the medical capabilities of the health sector.

We can find the solution of the optimal control model by using PMP. The Lagrangian function is as follows [26]:

$$
\begin{aligned}
L= & \sum_{t=0}^{T-1}-\{x(t)+y(t)\}^{2}+\sum_{t=0}^{T-1} \lambda_{i}(t+1)[\beta(t) I(t)-\{\mu(t)+x(t)\} I(t) \\
& -\{N(t)+y(t)\} I(t)-I(t+1)+I(t)]+\sum_{t=0}^{T-1} \lambda_{r}(t+1)[\{\mu(t)+x(t)\} I(t) \\
& -R(t+1)+R(t)]+\sum_{t=0}^{T-1} \lambda_{d}(t+1)[\{N(t)+y(t)\} I(t)-D(t+1)+D(t)]
\end{aligned}
$$

A Hamiltonian function is as follows:

$$
\begin{aligned}
H(t)= & -\{x(t)+y(t)\}^{2}+\lambda_{i}(t+1)[\beta(t) I(t)-\{\mu(t)+x(t)\} I(t)-\{N(t)+y(t)\} I(t)] \\
& +\lambda_{r}(t+1)[\{\mu(t)+x(t)\} I(t)]+\lambda_{d}(t+1)[\{N(t)+y(t)\} I(t)]
\end{aligned}
$$

Substitute Eq. (6) into Eq. (5), yields:

$$
\begin{aligned}
L= & \sum_{t=0}^{T-1}\left[H(t)-\lambda_{i}(t+1)\{I(t+1)-I(t)\}-\lambda_{r}(t+1)\{R(t+1)-R(t)\}\right. \\
& \left.-\lambda_{d}(t+1)\{D(t+1)-D(t)\}\right]
\end{aligned}
$$

Derive the Eq. (7) with respect to $I(t), R(t), D(t)$, separately, yields:

$$
\begin{gathered}
\lambda_{i}(t+1)[\beta(t)-\{\mu(t)+x(t)\}-\{N(t)+y(t)\}]+\lambda_{r}(t+1)\{\mu(t)+x(t)\} \\
+\lambda_{d}(t+1)\{N(t)+y(t)\}+\lambda_{i}(t+1)-\lambda_{i}(t)=0, \\
\lambda_{r}(t+1)-\lambda_{r}(t)=0, \\
\lambda_{d}(t+1)-\lambda_{d}(t)=0,
\end{gathered}
$$

The adjoint equations can be found from Eqs. (8)-(10) is as follows: 


$$
\begin{aligned}
\Delta \lambda_{i}(t)= & -\beta(t) \lambda_{i}(t+1)+\{\mu(t)+x(t)\}\left[\lambda_{i}(t+1)-\lambda_{r}(t+1)\right] \\
& +\{N(t)+y(t)\}\left[\lambda_{i}(t+1)-\lambda_{d}(t+1)\right],
\end{aligned}
$$

$$
\begin{aligned}
& \Delta \lambda_{r}(t)=0, \\
& \Delta \lambda_{d}(t)=0 .
\end{aligned}
$$

From Eq. (11), we get:

$$
\lambda_{i}(t+1)=\frac{1}{[1+\beta(t)-\{\mu(t)+x(t)\}-\{N(t)+y(t)\}]}\left[\lambda_{i}(t)-\{\mu(t)+x(t)\} \lambda_{r}(t+1)-\{N(t)+y(t)\} \lambda_{d}(t+1)\right]
$$

Derive the Eq. (7) with respect to $x(t), y(t)$, separately, yields:

$$
\begin{aligned}
& -2\{x(t)+y(t)\}-\lambda_{i}(t+1) I(t)+\lambda_{r}(t+1) I(t)=0, \\
& -2\{x(t)+y(t)\}-\lambda_{i}(t+1) I(t)+\lambda_{d}(t+1) I(t)=0 .
\end{aligned}
$$

From Eqs. (15) and (16), we get:

$$
\lambda_{r}(t+1)=\lambda_{d}(t+1)
$$

Rearrange Eq. (2), yields:

$$
I(t+1)=[1+\beta(t)-\{\mu(t)+x(t)\}-\{N(t)+y(t)\}] I(t)
$$

From Eq. (14), we get:

$$
\begin{aligned}
& {[1+\beta(t)-\{\mu(t)+x(t)\}-\{N(t)+y(t)\}]} \\
& \quad=\frac{1}{\lambda_{i}(t+1)}\left[\lambda_{i}(t)-\{\mu(t)+x(t)\} \lambda_{r}(t+1)-\{N(t)+y(t)\} \lambda_{d}(t+1)\right] .
\end{aligned}
$$

By substituting Eq. (19) into Eq. (18), yields:

$$
I(t+1)=\frac{I(t)}{\lambda_{i}(t+1)}\left[\lambda_{i}(t)-\{\mu(t)+x(t)\} \lambda_{r}(t+1)-\{N(t)+y(t)\} \lambda_{d}(t+1)\right]
$$

Equation (20) represents the total number of inpatients over time. From Eqs. (3) and (20), we can find the total number of recovered cases over time is as follows:

$$
R(t+1)=R(t)+\frac{\{\mu(t)+x(t)\} I(t+1) \lambda_{i}(t+1)}{\left[\lambda_{i}(t)-\{\mu(t)+x(t)\} \lambda_{r}(t+1)-\{N(t)+y(t)\} \lambda_{d}(t+1)\right]}
$$


We can find the total number of death cases over time by substituting Eq. (20) into Eq. (4) is as follows:

$$
D(t+1)=D(t)+\frac{\{N(t)+y(t)\} I(t+1) \lambda_{i}(t+1)}{\left[\lambda_{i}(t)-\{\mu(t)+x(t)\} \lambda_{r}(t+1)-\{N(t)+y(t)\} \lambda_{d}(t+1)\right]}
$$

Now, the value of control variables is as follows:

$$
\begin{aligned}
& y(t)=\left\{\begin{array}{lr}
-\gamma & \text { if } \gamma \leq N \\
-N & O . W .
\end{array}\right. \\
& x(t)=\left\{\begin{array}{cc}
\delta & \text { if } y(t)=0 \\
\gamma & O . W .
\end{array}\right. \\
& x(t)=y(t)=0 ; \text { actual cases }
\end{aligned}
$$

where $\gamma$ and $\delta$ are deterministic values.

Equation (23) achieves the condition of a nonnegative value of the death rate. Initially the value of control variables is zero, which means the model represents the actual cases that confirmed with the real percentage of new cases, recovered, and death is as follows:

$$
\beta_{t}=\frac{c_{t+1}}{I_{t}} ; \mu_{t}=\frac{r_{t+1}}{I_{t}} ; N_{t}=\frac{d_{t+1}}{I_{t}}
$$

where $c, r$, and $d$ represent the daily cases of new cases, recover, and death, respectively.

To fit the model with the real data of the COVID-19 cases, the initial values must be as follows:

$$
I_{1}=\frac{i_{1}}{\pi} ; R_{1}=\frac{r_{1}}{\pi} ; D_{1}=\frac{d_{1}}{\pi} ; \lambda_{i}(1)=\frac{c_{1}}{\pi}
$$

where $i$ represents the inpatient cases, and $\pi$ any fixed value, such as 10,000 .

The results of the model will be percentages that must be multiplied by $\pi$ to convert it to the integer numbers.

Then introduce the effect of the health sector capabilities by changing the values of control variables.

According to the values of control variables, there are three strategies are as follows:

- $x(t)$ represents increase the medical capabilities for health sector to increase the recovery cases. This means a decrease in the numbers of inpatient and death cases. 
- $y(t)$ represents increase the medical capabilities to decrease the death cases. This means an increase in the rates of inpatient and recover cases. This strategy focuses on the critical cases.

- Increasing the medical capabilities with the values of the two control variables are equal regardless of the signal. This means the number of inpatient cases stay without change. This strategy focuses on the all cases, so it represents the optimal strategy.

Finally, the solution of the optimal control model depends on Eqs. (12-14, 17, 20-22).

\section{Numerical results}

The study deals with COVID-19 cases in five countries: Argentina, Hungary, Egypt, Malaysia and Iraq. Approximately 2750 confirmed cases in each country represent the study period. The study period begins from registering more than 100 cases in each country, so the length of the period is more than one month. Tables 1, 2, 3, 4 and 5 (see "Appendix") show the number of COVID-19 cases in countries and parameter values of the model $(\beta, \mu, N)$ by using Eq. (26).

Figure 1 shows the results of the three strategies and the actual case of injuries $(x=y=0)$ in Argentina. The length of the study period is 30 days from 128 to 2758 confirmed cases.

From Fig. 1, we can deduce that the number of inpatient of the third strategy (green line) is the same in the actual case (blue circle). Increase the

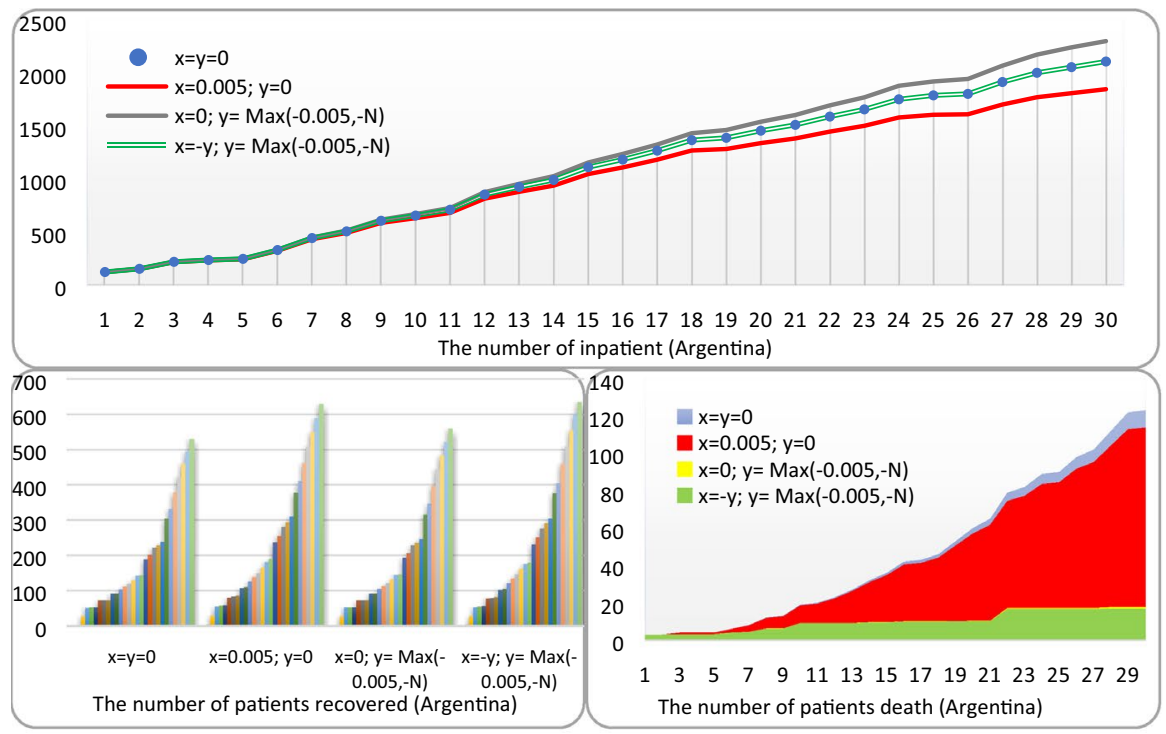

Fig. 1 The results of the optimal control model (Argentina) 


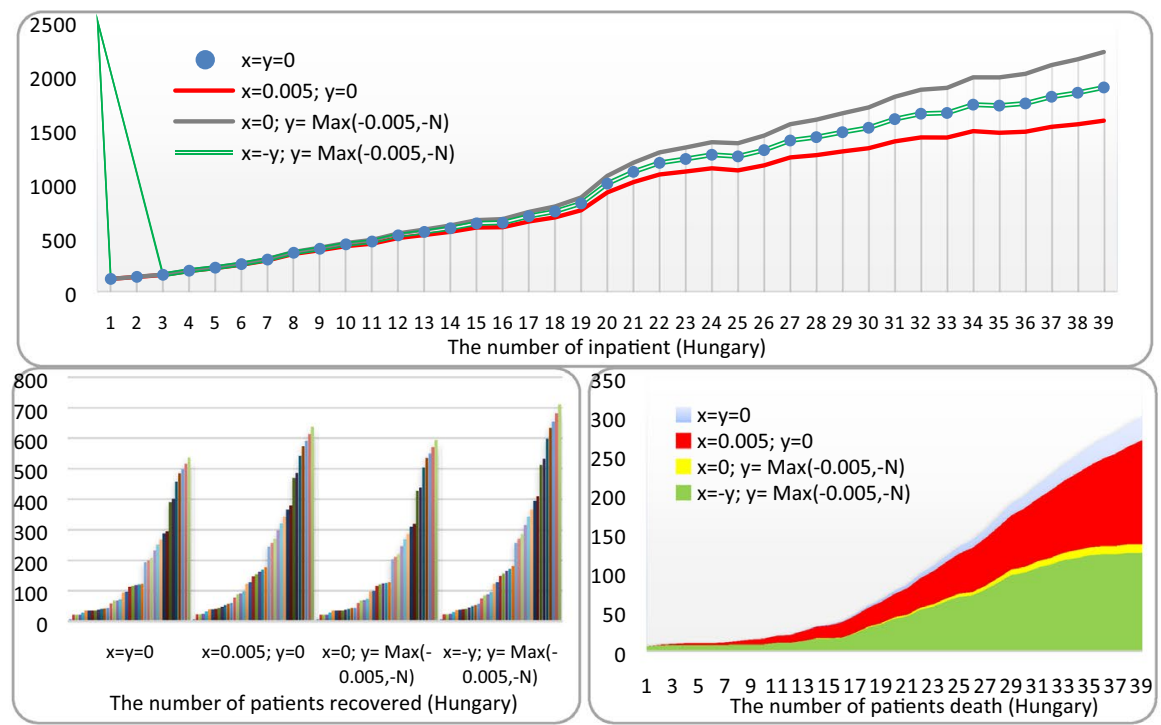

Fig. 2 The results of the optimal control model (Hungary)

medical capabilities affect only on the numbers of recovering and death with the same patients number. This means increased the recover cases by $0.2 \%$, while a significant decrease the death cases (green area) by 0.861 . A difference in percentages back to the big difference between the actual numbers of recovering and death cases.

The first strategy leads to decrease the number of inpatient (red line) by 0.123 . At the same time a significant increase the recovers cases and decrease the death cases (red area) by 0.187 and 0.073 , respectively.

The opposite case (the second strategy) leads to increase the number of inpatient (grey line) by 0.091 due to decrease the death cases. At the same time a slight increase the recover cases and a significant decrease the death cases (yellow area) by 0.057 and 0.856 , respectively. Figure 2 shows the number of inpatient, recover and death cases in Hungary.

The length of the study period is 39 days from 131 to 2727 confirmed cases. This means COVID-19 cases spreads in Argentina is faster than Hungary. From Fig. 2, the number of cases a significant increase 17 days later of the beginning of the study period (April 7th). The third strategy leads to increase the recover cases and a significant decrease the death cases (green area) by 0.325 and 0.581 , respectively. This means the most of the actual daily percentages of death are higher than 0.005 over the study period.

The first strategy leads to decrease the number of inpatient (red line) by 0.162 . At the same time increase the recover cases and decrease the death cases (red area) by 0.191 and 0.102 , respectively. The low change percentage of the recovery cases represent the best health sector. Thus, the health sector in Argentina is better than in Hungary, according to the change percentage of the recovery cases. 


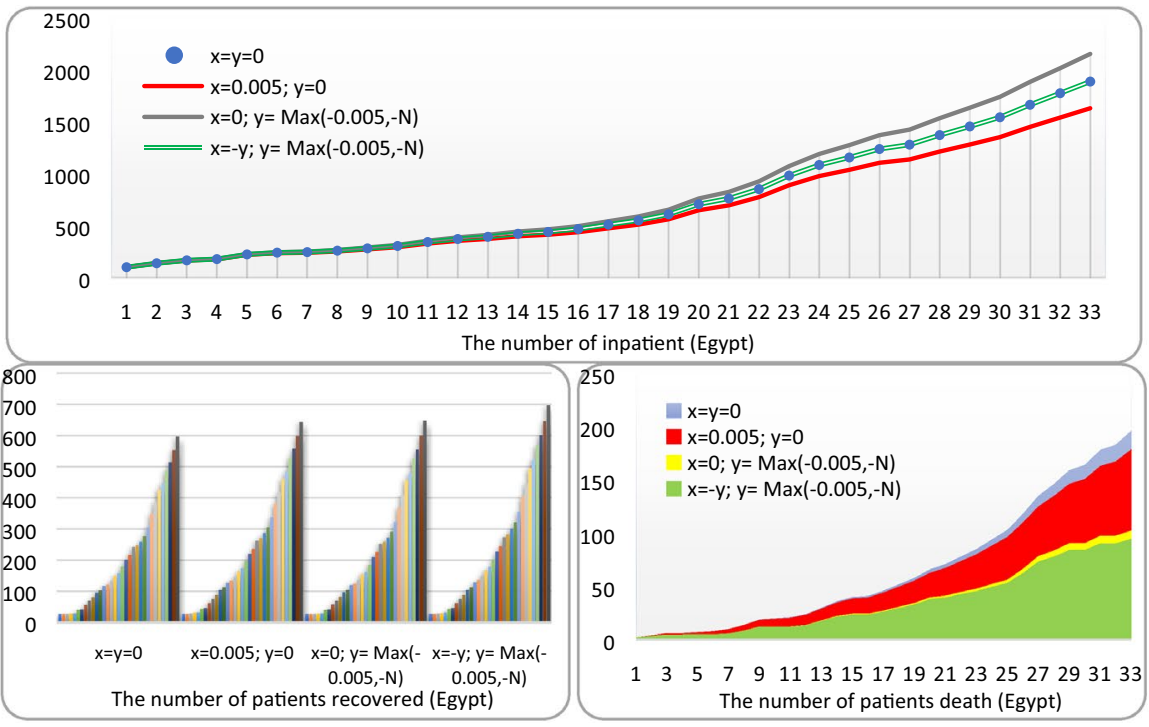

Fig. 3 The results of the optimal control model (Egypt)

Increase in the number of inpatient (grey line) by 0.173 , according to the second strategy. At the same time a slight increase the recover cases and a significant decrease the death cases (yellow area) by 0.108 and 0.544 , respectively. The high change percentage represents the best health sector in the case of death cases. Thus, the health sector in Argentina is better than in Hungary. Figure 3 shows the number of inpatient, recover and death cases in Egypt.

The length of the study period is 33 days from 126 to 2673 confirmed cases. This means the ranking of countries, according to the speed of spreading of COVID-19 cases is Argentina, Egypt and Hungary. From Fig. 3, the number of cases a significant increase 19 days later of the beginning of the study period (April 2th). Increase in the recover cases and a significant decrease the death cases (green area), according to the third strategy by 0.17 and 0.517 , respectively. This means more than half of the actual daily percentages of death are higher than 0.005 over the study period.

The first strategy leads to decrease the number of inpatient (red line) by 0.136 . At the same time a slight increase the recovered cases and decrease the death cases (red area) by 0.079 and 0.088 , respectively. The ranking of the countries is Egypt, Argentina, and Hungary, according to the change percentage of the recovery cases.

Increase in the number of inpatient (grey line) by 0.141 , according to the second strategy. At the same time a slight increase the recover cases and a significant decrease the death cases (yellow area) by 0.086 and 0.478 , respectively. The ranking of the countries is Argentina, Hungary, and Egypt, according to the change percentage of the death cases. Figure 4 shows the number of inpatient, recover and death cases in Malaysia. 


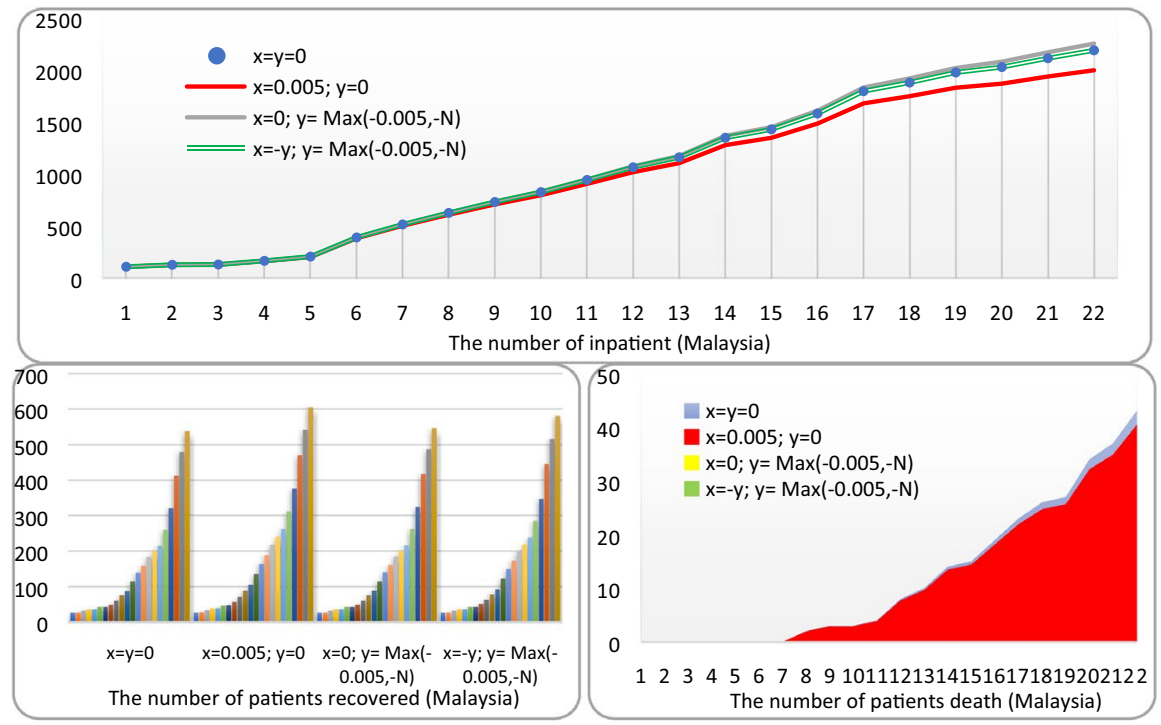

Fig. 4 The results of the optimal control model (Malaysia)

The length of the study period is 22 days from 129 to 2766 confirmed cases. This means the ranking of countries, according to the speed of spreading of COVID-19 cases is Malaysia, Argentina, Egypt and Hungary. From Fig. 4, the number of cases a significant increase 6 days later of the beginning of the study period (March 15th). The number of death cases is zero, according to the second and third strategies. This means the actual daily percent of death are less than 0.005 , while the increase in the recover cases by 0.08 .

The first strategy leads to decrease the number of inpatient (red line) by 0.087 . At the same time a slight increase the recovered cases and decrease the death cases (red area) by 0.125 and 0.06 , respectively. The ranking of the countries is Egypt, Malaysia, Argentina, and Hungary, according to the changing percent of the recovery cases.

Increase in the number of inpatient (grey line) by 0.029 , according to the second strategy. At the same time a slight increase the recover cases by 0.016 percent. The ranking of the countries is Malaysia, Argentina, Hungary, and Egypt, according to the changing percent of the death cases. Figure 5 shows the number of inpatients, recover and death cases in Iraq.

The length of the study period is 55 days from 165 to 2767 confirmed cases. This means the ranking of countries is Malaysia, Argentina, Egypt, Hungary and Iraq, according to the speed of spreading. From Fig. 5, the number of cases decreases 27 days later of the beginning of the study period (April 12th) and increase again 43 days later (April 28th). The third strategy leads to increase in the recover cases by $0.037 \%$, while a significant decrease the death cases (green area) by 0.601 . This means less than half of the actual daily percentages of death are higher than 0.005 over the study period. 


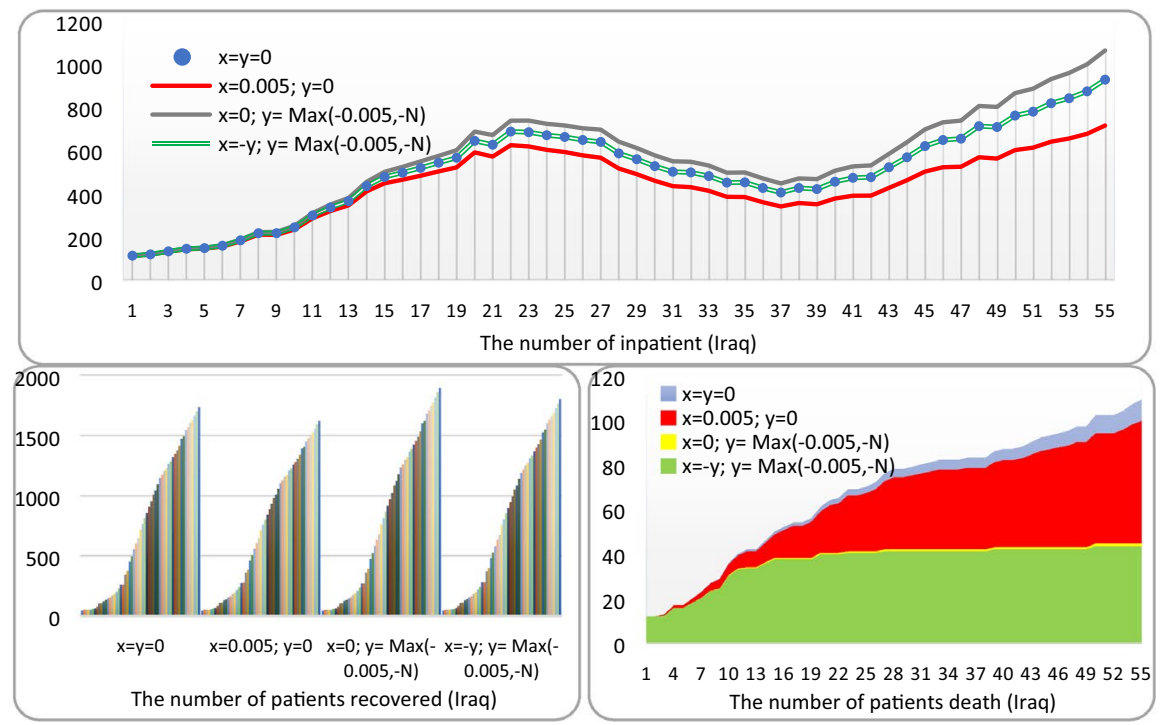

Fig. 5 The results of the optimal control model (Iraq)

The first strategy leads to decrease the number of inpatient (red line) by 0.229. At the same time a slight decrease in the recover and death cases (red area) by 0.066 and $0.087 \%$, respectively.

Increase in the number of inpatient (grey line) by $0.146 \%$, according to the second strategy. At the same time a slight increase the recover cases and a significant decrease the death cases (yellow area) by 0.092 and 0.59 , respectively.

Overall, the speed of COVID-19 spread depends on many factors, such as health awareness, tourism, modern technology using. The ranking of countries is Malaysia, Argentina, Egypt, Hungary and Iraq. For example, one of the reasons of the speed of spreading of COVID-19 cases in Malaysia is a gathering of thousands of people in one place on March 14. The ranking of the countries is Iraq, Egypt, Malaysia, Argentina, and Hungary, according to the first strategy (see Fig. 6). Meanwhile, Malaysia, Argentina, Iraq, Hungary, and Egypt, represents the ranking, according to the second strategy (see Fig. 7).

The important point is to determine the effect of developing the medical capabilities on the number of the recover and death cases. Figures 6, 7 and 8 represent a change of percentages of inpatient (I), recovery (R) and death (D), according to the change in control variable's value.

From Fig. 6, a small change in the recovery percent (green line) means better health sector (Iraq), and vice versa (Hungary). Meanwhile, a big change in the death percent (red line) means better health sector (Malaysia), and vice versa (Egypt) (see Fig. 7. From Fig. 8, there is no change in the percent of inpatients as a result to the values of the two control variables are equal regardless of the signal. 


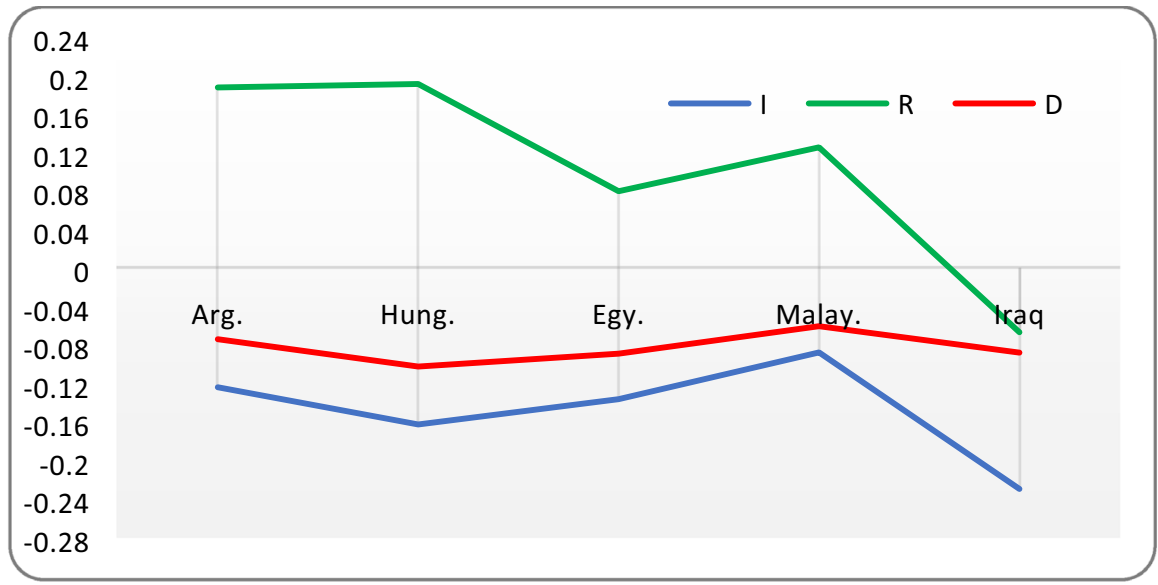

Fig. 6 Percent change, according to $x=0.005$ and $y=0$

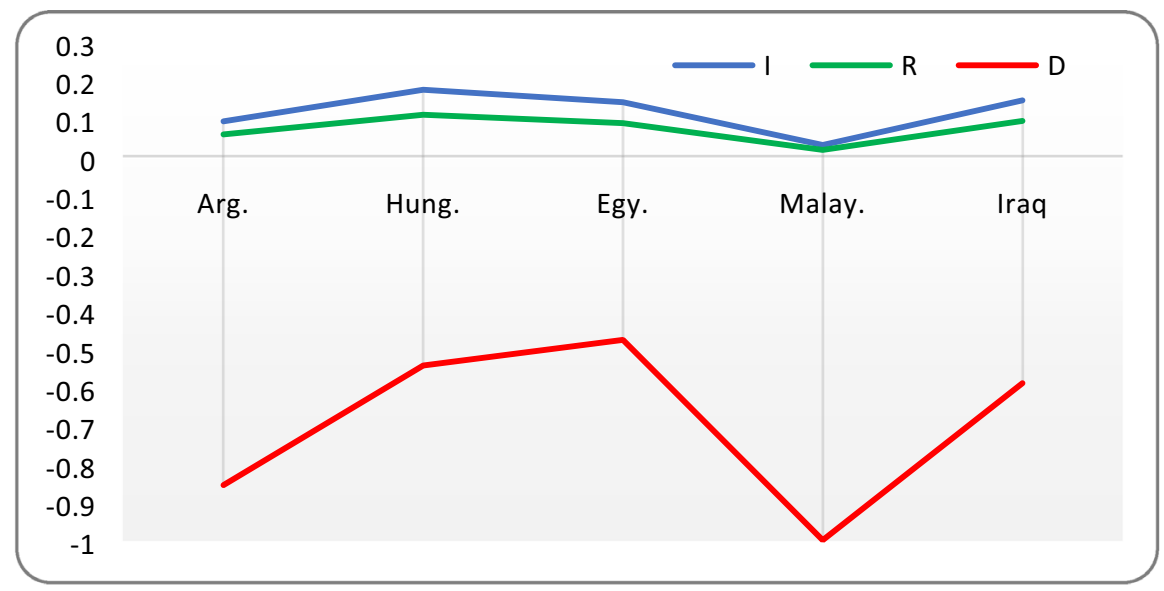

Fig. 7 Percent change, according to $x=0$ and $y=\operatorname{Max}(-0.005,-N)$

\section{Conclusion}

We developed an optimal control model of COVID-19 pandemic spreading. The health sector performance in Argentina, Hungary, Egypt, Malaysia, and Iraq, was discussed. The explicit solution of the model using the Pontryagin maximum principle was derived. At first, we formulated an optimal control model to fit the real case of COVID-19 in the countries. Control variables $x(t)$ and $y(t)$ representing the percentage of change in the rates of recovering and death, respectively. Zero value of the control variables representing the actual data of COVID-19 cases. Then, changed the value of the control variables, according to the three 


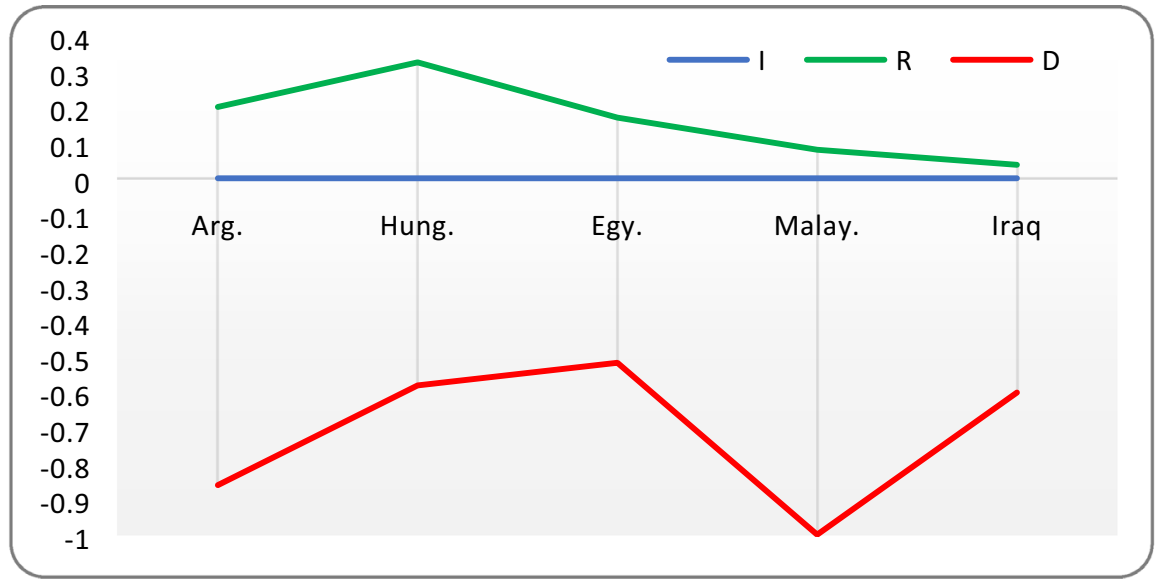

Fig. 8 Percent change, according to $x=0.005$ and $y=\operatorname{Max}(-0.005,-N)$

strategies of the health sector development. Finally, we determined the ranking of countries based on the change in the recovering and death percent.

It has been shown that speed of COVID-19 spreading (from 100 to 2750 cases) in Malaysia was the fastest with 22 days, and vice versa in Iraq with 55 days. The first strategy focused on increase the recovery cases by increase the medical capabilities by a specific percent. The ranking of the countries was Iraq, Egypt, Malaysia, Argentina, and Hungary. Meanwhile, the second strategy focused on reducing the death cases by increase the medical. The ranking was Malaysia, Argentina, Iraq, Hungary, and Egypt, according to the change percentage of the death cases. A change in the recovery and death cases without change in inpatient cases was the third strategy. Development the health sector by a specific percent $(0.5 \%)$ led to reduce the death cases. Malaysia with the highest percent $(100 \%)$ and Egypt with the lowest percent (48\%). Meanwhile, $1.6 \%$ and $8.6 \%$ represented the increase in the recover cases in Malaysia and Egypt, respectively.

Our model can apply in other countries to determine the health sector performance and development percent that its need. Also, with other factors, such as isolation and communications, that can affect on pandemic spreading.

\section{Availability of data and material}

The datasets generated and/or analysed during the current study are available in the [https://www.worldometers.info/coronavirus/country/argentina/], [https ://www.worldometers.info/coronavirus/country/hungary/], [https://www.coronatracker.com/country/hungary/]. [https://www.who.int/emergencies/diseases/ novel-coronavirus-2019/situation-reports] 
Acknowledgements Not Applicable.

Author contributions Authors' contributions: AK [Sects. 3 and 4]; BK [Sects. 1, 2, and 5].

Funding Not Applicable.

\section{Complaince with ethical standards}

Conflict of interest The authors declare that they have no competing interests.

\section{Appendix}

See Tables 1, 2, 3, 4 and 5.

Table 1 The number of COVID-19 cases in Argentina ${ }^{a}$

\begin{tabular}{|c|c|c|c|c|c|c|c|}
\hline Date & Cases & Recover & Death & N. cases & $\beta$ & $\mu$ & $N$ \\
\hline 14-Mar & 128 & 3 & 3 & 31 & 0.245902 & 0 & 0 \\
\hline 15-Mar & 158 & 3 & 3 & 30 & 0.440789 & 0 & 0.006579 \\
\hline 16-Mar & 225 & 3 & 4 & 67 & 0.188073 & 0.110092 & 0 \\
\hline 17-Mar & 266 & 27 & 4 & 41 & 0.148936 & 0.102128 & 0 \\
\hline 18-Mar & 301 & 51 & 4 & 35 & 0.349593 & 0.004065 & 0.00813 \\
\hline 19-Mar & 387 & 52 & 6 & 86 & 0.349544 & 0 & 0.006079 \\
\hline 20-Mar & 502 & 52 & 8 & 115 & 0.196833 & 0.045249 & 0.00905 \\
\hline 21-Mar & 589 & 72 & 12 & 87 & 0.2 & 0 & 0.00198 \\
\hline 22-Mar & 690 & 72 & 13 & 101 & 0.090909 & 0 & 0.009917 \\
\hline 23-Mar & 745 & 72 & 19 & 55 & 0.114679 & 0.029052 & 0.001529 \\
\hline 24-Mar & 820 & 91 & 20 & 75 & 0.205924 & 0 & 0.004231 \\
\hline 25-Mar & 966 & 91 & 23 & 146 & 0.103286 & 0.014085 & 0.004695 \\
\hline 26-Mar & 1054 & 103 & 27 & 88 & 0.085498 & 0.008658 & 0.005411 \\
\hline 27-Mar & 1133 & 111 & 32 & 79 & 0.133333 & 0.008081 & 0.00404 \\
\hline 28-Mar & 1265 & 119 & 36 & 132 & 0.079279 & 0.009009 & 0.005405 \\
\hline 29-Mar & 1353 & 129 & 42 & 88 & 0.08291 & 0.010998 & 0.000846 \\
\hline 30-Mar & 1451 & 142 & 43 & 98 & 0.081359 & 0.00079 & 0.00237 \\
\hline 31-Mar & 1554 & 143 & 46 & 103 & 0.054212 & 0.032967 & 0.005128 \\
\hline 1-Apr & 1628 & 188 & 53 & 74 & 0.062725 & 0.009373 & 0.005047 \\
\hline 2-Apr & 1715 & 201 & 60 & 87 & 0.055021 & 0.013755 & 0.003439 \\
\hline 3-Apr & 1795 & 221 & 65 & 80 & 0.065606 & 0.004639 & 0.009278 \\
\hline 4-Apr & 1894 & 228 & 79 & 99 & 0.05104 & 0.006301 & 0.00189 \\
\hline 5-Apr & 1975 & 238 & 82 & 81 & 0.100906 & 0.039275 & 0.00423 \\
\hline 6-Apr & 2142 & 303 & 89 & 167 & 0.037714 & 0.016 & 0.000571 \\
\hline 7-Apr & 2208 & 331 & 90 & 66 & 0.038612 & 0.026301 & 0.004477 \\
\hline 8-Apr & 2277 & 378 & 98 & 69 & 0.08884 & 0.024431 & 0.002221 \\
\hline 9-Apr & 2437 & 422 & 102 & 160 & 0.070047 & 0.019341 & 0.005227 \\
\hline 10-Apr & 2571 & 459 & 112 & 134 & 0.049 & 0.0175 & 0.005 \\
\hline 11-Apr & 2669 & 494 & 122 & 98 & 0.043351 & 0.017048 & 0.000487 \\
\hline 12-Apr & 2758 & 529 & 123 & 89 & & & \\
\hline
\end{tabular}

${ }^{a}$ https://www.worldometers.info/coronavirus/country/argentina/ 
Table 2 The number of COVID-19 cases in Hungary*

\begin{tabular}{|c|c|c|c|c|c|c|c|}
\hline Date & Cases & Recover & Death & N. cases & $\beta$ & $\mu$ & $N$ \\
\hline 22-Mar & 131 & 6 & 6 & 28 & 0.302521 & 0.12605 & 0.016807 \\
\hline 23-Mar & 167 & 21 & 8 & 36 & 0.144928 & 0 & 0.007246 \\
\hline 24-Mar & 187 & 21 & 9 & 20 & 0.248408 & 0 & 0.006369 \\
\hline 25-Mar & 226 & 21 & 10 & 39 & 0.179487 & 0.035897 & 0 \\
\hline 26-Mar & 261 & 28 & 10 & 35 & 0.174888 & 0.026906 & 0 \\
\hline 27-Mar & 300 & 34 & 10 & 39 & 0.167969 & 0 & 0.003906 \\
\hline 28-Mar & 343 & 34 & 11 & 43 & 0.218121 & 0 & 0.006711 \\
\hline 29-Mar & 408 & 34 & 13 & 65 & 0.108033 & 0 & 0.00554 \\
\hline 30-Mar & 447 & 34 & 15 & 39 & 0.113065 & 0.007538 & 0.002513 \\
\hline 31-Mar & 492 & 37 & 16 & 45 & 0.075171 & 0.006834 & 0.009112 \\
\hline 1-Apr & 525 & 40 & 20 & 33 & 0.129032 & 0.004301 & 0.002151 \\
\hline 2-Apr & 585 & 42 & 21 & 60 & 0.072797 & 0.001916 & 0.009579 \\
\hline 3-Apr & 623 & 43 & 26 & 38 & 0.099278 & 0.027076 & 0.01083 \\
\hline 4-Apr & 678 & 58 & 32 & 55 & 0.093537 & 0.013605 & 0.003401 \\
\hline 5-Apr & 733 & 66 & 34 & 55 & 0.017378 & 0.00158 & 0.006319 \\
\hline 6-Apr & 744 & 67 & 38 & 11 & 0.114241 & 0.00626 & 0.014085 \\
\hline 7-Apr & 817 & 71 & 47 & 73 & 0.111588 & 0.032904 & 0.015737 \\
\hline 8-Apr & 895 & 94 & 58 & 78 & 0.114401 & 0.002692 & 0.010767 \\
\hline 9-Apr & 980 & 96 & 66 & 85 & 0.256724 & 0.01956 & 0.013447 \\
\hline 10-Apr & 1190 & 112 & 77 & 210 & 0.11988 & 0.002997 & 0.007992 \\
\hline 11-Apr & 1310 & 115 & 85 & 120 & 0.09009 & 0.002703 & 0.012613 \\
\hline 12-Apr & 1410 & 118 & 99 & 100 & 0.040235 & 0.001676 & 0.008382 \\
\hline 13-Apr & 1458 & 120 & 109 & 48 & 0.043938 & 0.001627 & 0.010578 \\
\hline 14-Apr & 1512 & 122 & 122 & 54 & 0.052839 & 0.055205 & 0.009464 \\
\hline 15-Apr & 1579 & 192 & 134 & 67 & 0.05826 & 0.005587 & 0.006385 \\
\hline 16-Apr & 1652 & 199 & 142 & 73 & 0.084668 & 0.006102 & 0.010679 \\
\hline 17-Apr & 1763 & 207 & 156 & 111 & 0.050714 & 0.017143 & 0.011429 \\
\hline 18-Apr & 1834 & 231 & 172 & 71 & 0.057303 & 0.013277 & 0.01188 \\
\hline 19-Apr & 1916 & 250 & 189 & 82 & 0.046039 & 0.01151 & 0.00677 \\
\hline 20-Apr & 1984 & 267 & 199 & 68 & 0.075099 & 0.013175 & 0.009223 \\
\hline 21-Apr & 2098 & 287 & 213 & 114 & 0.043805 & 0.005006 & 0.007509 \\
\hline 22-Apr & 2168 & 295 & 225 & 70 & 0.070388 & 0.057646 & 0.008495 \\
\hline 23-Apr & 2284 & 390 & 239 & 116 & 0.059819 & 0.006647 & 0.006647 \\
\hline 24-Apr & 2383 & 401 & 250 & 99 & 0.034642 & 0.03291 & 0.006928 \\
\hline 25-Apr & 2443 & 458 & 262 & 60 & 0.033082 & 0.01567 & 0.005804 \\
\hline 26-Apr & 2500 & 485 & 272 & 57 & 0.047619 & 0.007458 & 0.00459 \\
\hline 27-Apr & 2583 & 498 & 280 & 83 & 0.036565 & 0.009972 & 0.006094 \\
\hline 28-Apr & 2649 & 516 & 291 & 66 & 0.042345 & 0.010858 & 0.004886 \\
\hline 29-Apr & 2727 & 536 & 300 & 78 & & & \\
\hline
\end{tabular}

*https://www.worldometers.info/coronavirus/country/hungary/

*https://www.coronatracker.com/country/hungary/ 
Table 3 The number of COVID-19 cases in Egypt ${ }^{\mathrm{a}}$

\begin{tabular}{|c|c|c|c|c|c|c|c|}
\hline Date & Cases & Recover & Death & N. Cases & $\beta$ & $\mu$ & $N$ \\
\hline 15-Mar & 126 & 26 & 2 & 16 & 0.408163 & 0 & 0.020408 \\
\hline 16-Mar & 166 & 26 & 4 & 40 & 0.220588 & 0 & 0.014706 \\
\hline 17-Mar & 196 & 26 & 6 & 30 & 0.085366 & 0.012195 & 0 \\
\hline 18-Mar & 210 & 28 & 6 & 14 & 0.261364 & 0 & 0.005682 \\
\hline 19-Mar & 256 & 28 & 7 & 46 & 0.131222 & 0.049774 & 0.004525 \\
\hline 20-Mar & 285 & 39 & 8 & 29 & 0.037815 & 0.008403 & 0.008403 \\
\hline 21-Mar & 294 & 41 & 10 & 9 & 0.135802 & 0.061728 & 0.016461 \\
\hline 22-Mar & 327 & 56 & 14 & 33 & 0.151751 & 0.046693 & 0.019455 \\
\hline 23-Mar & 366 & 68 & 19 & 39 & 0.129032 & 0.043011 & 0.003584 \\
\hline 24-Mar & 402 & 80 & 20 & 36 & 0.178808 & 0.049669 & 0.003311 \\
\hline 25-Mar & 456 & 95 & 21 & 54 & 0.114706 & 0.020588 & 0.008824 \\
\hline 26-Mar & 495 & 102 & 24 & 39 & 0.111111 & 0.03794 & 0.01626 \\
\hline 27-Mar & 536 & 116 & 30 & 41 & 0.102564 & 0.012821 & 0.015385 \\
\hline 28-Mar & 576 & 121 & 36 & 40 & 0.078759 & 0.026253 & 0.009547 \\
\hline 29-Mar & 609 & 132 & 40 & 33 & 0.107551 & 0.04119 & 0.002288 \\
\hline 30-Mar & 656 & 150 & 41 & 47 & 0.116129 & 0.015054 & 0.010753 \\
\hline 31-Mar & 710 & 157 & 46 & 54 & 0.136095 & 0.043393 & 0.011834 \\
\hline 1-Apr & 779 & 179 & 52 & 69 & 0.156934 & 0.040146 & 0.010949 \\
\hline 2-Apr & 865 & 201 & 58 & 86 & 0.19802 & 0.024752 & 0.013201 \\
\hline 3-Apr & 985 & 216 & 66 & 120 & 0.12091 & 0.035562 & 0.007112 \\
\hline 4-Apr & 1070 & 241 & 71 & 85 & 0.135884 & 0.007916 & 0.009235 \\
\hline 5-Apr & 1173 & 247 & 78 & 103 & 0.175708 & 0.014151 & 0.008255 \\
\hline 6-Apr & 1322 & 259 & 85 & 149 & 0.130879 & 0.017382 & 0.009202 \\
\hline 7-Apr & 1450 & 276 & 94 & 128 & 0.101852 & 0.026852 & 0.008333 \\
\hline 8-Apr & 1560 & 305 & 103 & 110 & 0.12066 & 0.037326 & 0.013021 \\
\hline 9-Apr & 1699 & 348 & 118 & 139 & 0.077048 & 0.029197 & 0.013788 \\
\hline 10-Apr & 1794 & 384 & 135 & 95 & 0.113725 & 0.032941 & 0.008627 \\
\hline 11-Apr & 1939 & 426 & 146 & 145 & 0.085589 & 0.015362 & 0.00951 \\
\hline 12-Apr & 2056 & 447 & 159 & 117 & 0.092414 & 0.028276 & 0.003448 \\
\hline 13-Apr & 2190 & 488 & 164 & 134 & 0.104031 & 0.016905 & 0.009103 \\
\hline 14-Apr & 2350 & 514 & 178 & 160 & 0.093486 & 0.023522 & 0.003016 \\
\hline 15-Apr & 2505 & 553 & 183 & 155 & 0.094969 & 0.024308 & 0.007349 \\
\hline 16-Apr & 2673 & 596 & 196 & 168 & & & \\
\hline
\end{tabular}

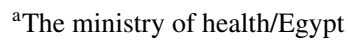


Table 4 The number of COVID-19 cases in Malaysia ${ }^{\mathrm{a}}$

\begin{tabular}{|c|c|c|c|c|c|c|c|}
\hline Date & Cases & Recover & Death & N. Cases & $\beta$ & $\mu$ & $N$ \\
\hline 10-Mar & 129 & 25 & 0 & 12 & 0.192308 & 0.009615 & 0 \\
\hline 11-Mar & 149 & 26 & 0 & 20 & 0.073171 & 0.04878 & 0 \\
\hline 12-Mar & 158 & 32 & 0 & 9 & 0.309524 & 0.031746 & 0 \\
\hline 13-Mar & 197 & 36 & 0 & 39 & 0.254658 & 0 & 0 \\
\hline 14-Mar & 238 & 36 & 0 & 41 & 0.940594 & 0.029703 & 0 \\
\hline 15-Mar & 428 & 42 & 0 & 190 & 0.323834 & 0 & 0 \\
\hline 16-Mar & 553 & 42 & 0 & 125 & 0.234834 & 0.013699 & 0.003914 \\
\hline 17-Mar & 673 & 49 & 2 & 120 & 0.188103 & 0.017685 & 0.001608 \\
\hline 18-Mar & 790 & 60 & 3 & 117 & 0.151307 & 0.020633 & 0 \\
\hline 19-Mar & 900 & 75 & 3 & 110 & 0.158151 & 0.014599 & 0.001217 \\
\hline 20-Mar & 1030 & 87 & 4 & 130 & 0.162939 & 0.028754 & 0.00426 \\
\hline 21-Mar & 1183 & 114 & 8 & 153 & 0.115928 & 0.023563 & 0.001885 \\
\hline 22-Mar & 1306 & 139 & 10 & 123 & 0.183232 & 0.017286 & 0.003457 \\
\hline 23-Mar & 1518 & 159 & 14 & 212 & 0.07881 & 0.017844 & 0.000743 \\
\hline 24-Mar & 1624 & 183 & 15 & 106 & 0.120617 & 0.01122 & 0.002805 \\
\hline 25-Mar & 1796 & 199 & 19 & 172 & 0.148923 & 0.010139 & 0.002535 \\
\hline 26-Mar & 2031 & 215 & 23 & 235 & 0.072504 & 0.02454 & 0.001673 \\
\hline 27-Mar & 2161 & 259 & 26 & 130 & 0.084755 & 0.032516 & 0.000533 \\
\hline 28-Mar & 2320 & 320 & 27 & 159 & 0.076026 & 0.046123 & 0.003548 \\
\hline 29-Mar & 2470 & 411 & 34 & 150 & 0.077037 & 0.03358 & 0.001481 \\
\hline 30-Mar & 2626 & 479 & 37 & 156 & 0.066351 & 0.027488 & 0.002844 \\
\hline 31-Mar & 2766 & 537 & 43 & 140 & & & \\
\hline
\end{tabular}

${ }^{\mathrm{a}}$ The ministry of health/Malaysia 
Table 5 The number of COVID-19 cases in Iraq ${ }^{\mathrm{a}}$

\begin{tabular}{|c|c|c|c|c|c|c|c|}
\hline Date & Cases & Recover & Death & N. Cases & $\beta$ & $\mu$ & $N$ \\
\hline 17-Mar & 165 & 43 & 12 & 11 & 0.10909 & 0.054545 & 0 \\
\hline 18-Mar & 177 & 49 & 12 & 12 & 0.12931 & 0 & 0.008621 \\
\hline 19-Mar & 192 & 49 & 13 & 15 & 0.12308 & 0 & 0.030769 \\
\hline 20-Mar & 208 & 49 & 17 & 16 & 0.04225 & 0.021127 & 0 \\
\hline 21-Mar & 214 & 52 & 17 & 6 & 0.13103 & 0.034483 & 0.02069 \\
\hline 22-Mar & 233 & 57 & 20 & 19 & 0.21154 & 0.032051 & 0.019231 \\
\hline 23-Mar & 266 & 62 & 23 & 33 & 0.27624 & 0.071823 & 0.022099 \\
\hline 24-Mar & 316 & 75 & 27 & 50 & 0.14019 & 0.130841 & 0.009346 \\
\hline 25-Mar & 346 & 103 & 29 & 30 & 0.16822 & 0.009346 & 0.03271 \\
\hline 26-Mar & 382 & 105 & 36 & 36 & 0.31535 & 0.070539 & 0.016598 \\
\hline 27-Mar & 458 & 122 & 40 & 76 & 0.16216 & 0.030405 & 0.006757 \\
\hline 28-Mar & 506 & 131 & 42 & 48 & 0.12312 & 0.036036 & 0 \\
\hline 29-Mar & 547 & 143 & 42 & 41 & 0.22928 & 0.024862 & 0.01105 \\
\hline 30-Mar & 630 & 152 & 46 & 83 & 0.14815 & 0.041667 & 0.009259 \\
\hline 31-Mar & 694 & 170 & 50 & 64 & 0.07173 & 0.025316 & 0.004219 \\
\hline 1-Apr & 728 & 182 & 52 & 34 & 0.08907 & 0.040486 & 0.004049 \\
\hline 2-Apr & 772 & 202 & 54 & 44 & 0.09302 & 0.046512 & 0 \\
\hline 3-Apr & 820 & 226 & 54 & 48 & 0.10741 & 0.061111 & 0.003704 \\
\hline 4-Apr & 878 & 259 & 56 & 58 & 0.14742 & 0 & 0.008881 \\
\hline 5-Apr & 961 & 259 & 61 & 83 & 0.1092 & 0.132605 & 0.00468 \\
\hline 6-Apr & 1031 & 344 & 64 & 70 & 0.14607 & 0.046549 & 0.001605 \\
\hline 7-Apr & 1122 & 373 & 65 & 91 & 0.11696 & 0.115497 & 0.005848 \\
\hline 8-Apr & 1202 & 452 & 69 & 80 & 0.04405 & 0.064611 & 0 \\
\hline 9-Apr & 1232 & 496 & 69 & 30 & 0.07046 & 0.08096 & 0.001499 \\
\hline 10-Apr & 1279 & 550 & 70 & 47 & 0.05918 & 0.07739 & 0.003035 \\
\hline 11-Apr & 1318 & 601 & 72 & 39 & 0.05271 & 0.060465 & 0.006202 \\
\hline 12-Apr & 1352 & 640 & 76 & 34 & 0.04088 & 0.121069 & 0.003145 \\
\hline 13-Apr & 1378 & 717 & 78 & 26 & 0.03774 & 0.084048 & 0 \\
\hline 14-Apr & 1400 & 766 & 78 & 22 & 0.02698 & 0.082734 & 0.001799 \\
\hline 15-Apr & 1415 & 812 & 79 & 15 & 0.03626 & 0.083969 & 0.001908 \\
\hline 16-Apr & 1434 & 856 & 80 & 19 & 0.09639 & 0.100402 & 0.002008 \\
\hline 17-Apr & 1482 & 906 & 81 & 48 & 0.06263 & 0.094949 & 0.00202 \\
\hline 18-Apr & 1513 & 953 & 82 & 31 & 0.05439 & 0.117155 & 0 \\
\hline 19-Apr & 1539 & 1009 & 82 & 26 & 0.07813 & 0.075893 & 0 \\
\hline 20-Apr & 1574 & 1043 & 82 & 35 & 0.06236 & 0.11804 & 0.002227 \\
\hline 21-Apr & 1602 & 1096 & 83 & 28 & 0.06856 & 0.118203 & 0 \\
\hline 22-Apr & 1631 & 1146 & 83 & 29 & 0.11443 & 0.062189 & 0 \\
\hline 23-Apr & 1677 & 1171 & 83 & 46 & 0.07329 & 0.078014 & 0.007092 \\
\hline 24-Apr & 1708 & 1204 & 86 & 31 & 0.13158 & 0.047847 & 0.002392 \\
\hline 25-Apr & 1763 & 1224 & 87 & 55 & 0.12611 & 0.086283 & 0 \\
\hline 26-Apr & 1820 & 1263 & 87 & 57 & 0.05745 & 0.048936 & 0.002128 \\
\hline 27-Apr & 1847 & 1286 & 88 & 27 & 0.17125 & 0.069767 & 0.004228 \\
\hline
\end{tabular}


Table 5 (continued)

\begin{tabular}{llllllll}
\hline Date & Cases & Recover & Death & N. Cases & $\beta$ & $\mu$ & $N$ \\
\hline 28-Apr & 1928 & 1319 & 90 & 81 & 0.14451 & 0.052023 & 0.003854 \\
29-Apr & 2003 & 1346 & 92 & 75 & 0.14513 & 0.051327 & 0.00177 \\
30-Apr & 2085 & 1375 & 93 & 82 & 0.11021 & 0.063209 & 0.001621 \\
1-May & 2153 & 1414 & 94 & 68 & 0.10233 & 0.091473 & 0.00155 \\
2-May & 2219 & 1473 & 95 & 66 & 0.11828 & 0.026114 & 0.003072 \\
3-May & 2296 & 1490 & 97 & 77 & 0.07052 & 0.076164 & 0 \\
4-May & 2346 & 1544 & 97 & 50 & 0.12057 & 0.038298 & 0.007092 \\
5-May & 2431 & 1571 & 102 & 85 & 0.06464 & 0.040897 & 0 \\
6-May & 2480 & 1602 & 102 & 49 & 0.08119 & 0.030928 & 0 \\
7-May & 2543 & 1626 & 102 & 63 & 0.07362 & 0.042945 & 0.002454 \\
8-May & 2603 & 1661 & 104 & 60 & 0.09069 & 0.048926 & 0.00358 \\
9-May & 2679 & 1702 & 107 & 76 & 0.10115 & 0.036782 & 0.002299 \\
10-May & 2767 & 1734 & 109 & 88 & & & \\
\hline
\end{tabular}

${ }^{\mathrm{a}}$ The ministry of health/Iraq

\section{References}

1. Wang, Z., Wang, J., He, J.: Active and effective measures for the care of patients with cancer during the COVID-19 spread in China. JAMA Oncol. 6(5), 631-632 (2020)

2. Chen, H., Guo, J., Wang, C., Luo, F., Yu, X., Zhang, W., et al.: Clinical characteristics and intrauterine vertical transmission potential of COVID-19 infection in nine pregnant women: a retrospective review of medical records. Lancet. 395(10226), 809-815 (2020)

3. Xu, Z., Shi, L., Wang, Y., Zhang, J., Huang, L., Zhang, C., et al.: Pathological findings of COVID19 associated with acute respiratory distress syndrome. Lancet Respir. Med. 8(4), 420-422 (2020)

4. Chen, X., Yang, Y., Huang, M., Lili, L., Zhang, X., Xu, J., et al.: Differences between COVID-19 and suspected then confirmed SARS-CoV-2-negative pneumonia: a retrospective study from a single center. J. Med. Virol. (2020)

5. World Health Organization (2020) Coronavirus disease 2019 (COVID-19): situation report, 69

6. Ai, T., Yang, Z., Hou, H., Zhan, C., Chen, C., Lv, W., et al.: Correlation of chest CT and RT-PCR testing in coronavirus disease 2019 (COVID-19) in China: a report of 1014 cases. Radiology. 2020, $200642(2020)$

7. Lipsitch, M., Swerdlow, D.L., Finelli, L.: Defining the epidemiology of Covid-19—studies needed. N. Engl. J. Med. 382(13), 1194-1196 (2020)

8. Gao, J., Tian, Z., Yang, X.: Breakthrough: Chloroquine phosphate has shown apparent efficacy in treatment of COVID-19 associated pneumonia in clinical studies. Biosci. Trends. 14(1), 72-73 (2020)

9. Zhou, F., Yu, T., Du, R., Fan, G., Liu, Y., Liu, Z., et al.: Clinical course and risk factors for mortality of adult inpatient with COVID-19 in Wuhan, China: a retrospective cohort study. Lancet. 395(10229) (2020)

10. Lee, S., Chowell, G., Castillo-Chávez, C.: Optimal control for pandemic influenza: the role of limited antiviral treatment and isolation. J. Theor. Biol. 265(2), 136-150 (2010)

11. Hansen, E., Day, T.: Optimal control of epidemics with limited resources. J. Math. Biol. 62(3), 423451 (2011)

12. Tuite, A.R., Tien, J., Eisenberg, M., Earn, D.J., Ma, J., Fisman, D.N.: Cholera epidemic in Haiti, 2010: using a transmission model to explain spatial spread of disease and identify optimal control interventions. Ann. Intern. Med. 154(9), 593-601 (2011) 
13. Rodrigues, H.S., Monteiro, M.T.T., Torres, D.F.: Vaccination models and optimal control strategies to dengue. Math. Biosci. 247, 1-12 (2014)

14. Rodrigues, P., Silva, C.J., Torres, D.F.: Cost-effectiveness analysis of optimal control measures for tuberculosis. Bull. Math. Biol. 76(10), 2627-2645 (2014)

15. Moualeu, D.P., Weiser, M., Ehrig, R., Deuflhard, P.: Optimal control for a tuberculosis model with undetected cases in Cameroon. Commun. Nonlinear Sci. Numer. Simul. 20(3), 986-1003 (2015)

16. Pang, L., Ruan, S., Liu, S., Zhao, Z., Zhang, X.: Transmission dynamics and optimal control of measles epidemics. Appl. Math. Comput. 256, 131-147 (2015)

17. Rachah, A., Torres, D.F.: Mathematical modelling, simulation, and optimal control of the 2014 Ebola outbreak in West Africa. Discret. Dyn. Nat. Soc. 2015, 842792 (2015)

18. Rachah, A., Torres, D.F.: Dynamics and optimal control of Ebola transmission. Math. Comput. Sci. 10(3), 331-342 (2016)

19. Gao, D.P., Huang, N.J.: Optimal control analysis of a tuberculosis model. Appl. Math. Model. 58, 47-64 (2018)

20. World Health Organization (2020) Coronavirus disease 2019 (COVID-19): situation report, 1

21. World Health Organization (2020) Coronavirus disease 2019 (COVID-19): situation report, 56

22. World Health Organization (2020) Coronavirus disease 2019 (COVID-19): situation report, 163

23. World Health Organization (2020) Coronavirus disease 2019 (COVID-19): situation report, 6

24. World Health Organization (2020) Coronavirus disease 2019 (COVID-19): situation report, 30

25. World Health Organization (2020) Coronavirus disease 2019 (COVID-19): situation report, 45

26. Sethi, S., Thompson, G.: Optimal Control Theory Application to Management Science and Economics, 2nd edn. Springer, New York (2020)

Publisher's Note Springer Nature remains neutral with regard to jurisdictional claims in published maps and institutional affiliations. 